\title{
DIFICULTADES EN TORNO A LA INTERPRETACIÓN CAYETANIANA DEL ENS: ESSE ESSENTIAE Y ESSE ACTUALIS EXISTENTIAE
}

\author{
DIFFICULTIES CONCERNING CAJETAN'S INTERPRETATION OF ENS: \\ ESSE ESSENTIAE Y ESSE ACTUALIS EXISTENTIAE
}

\author{
Ceferino P.D. Muñoz ${ }^{1}$ \\ CONICET / Universidad Nacional de Cuyo (Argentina)
}

Recibido: 04-11-2012

Aceptado: 11-01-2013

Resumen: Estudiaremos algunos textos de Tomás de Vio Cayetano a fin de comprender su concepción de ens y otras nociones anejas como las de esse essentiae y esse actualis existentiae. En este sentido, indagaremos sobre la posibilidad de ubicar la génesis de estas nociones en la letra de Aristóteles y de Tomás de Aquino o, en su defecto, en otros filósofos medievales. Asimismo, analizaremos ciertas consecuencias metafísicas que conllevaría el hablar en términos de "ser de la esencia" y "ser de la existencia actual".

Palabras-clave: Cayetano, Aristóteles, Santo Tomás, ens, esse essentiae, esse actualis existentiae.

\begin{abstract}
We will study some texts of Thomas de Vio Cajetan to understand his conception of ens and other notions such as attached and esse essentiae and actualis essentiae existentiae. In this sense, we will investigate the possibility of locating the genesis of these notions in the letter of Aristotle and Thomas Aquinas or, alternatively, in other medieval philosophers. Also discuss certain metaphysical consequences entail speaking in terms of "being of the essence" and "being of actual existence".
\end{abstract}

Key-words: Cajetan, Aristotle, Saint Thomas, ens, esse essentiae, esse actualis existentiae.

[1] (ceferinomm@hotmail.com) Doctorando en Filosofía (U.N.Cuyo-Argentina) y Becario de CONICET con el proyecto: "Ciencia y objetividad en el pensamiento de Cayetano. Reconsideración de su significación en el contexto de la filosofía medieval y moderna”. Es investigador libre del Instituto de Filosofía de la U.N.Cuyo e integrante de la Comisión Directiva de dicho Instituto. Miembro del Centro de Estudios Filosóficos Medievales". Forma parte del comité editorial de la revista de pensamiento medieval Scripta Mediaevalia. Docente de grado y de Posgrado. 


\section{La autoridad de Cayetano}

Es conocida la autoridad que han ejercido y siguen ejerciendo los comentarios de Cayetano a Tomás de Aquino. Distintas generaciones de tomistas desde el s. XVI en adelante se han nutrido de la exégesis cayetaniana; inclusive la edición leonina -la más importante hasta el momento de la obra del Aquinate-contiene las glosas del Cardenal de San Sixto a toda la Suma de Teología y a otros escritos del Angélico.

Sin embargo, desde hace unos años se ha puesto en tela de juicio la fidelidad doctrinal de algunas interpretaciones de Cayetano a su maestro, y sobre todo la particular exégesis de Tomás de Vio a la doctrina del actus essendi tomasiano.

En este contexto, nos proponemos en lo que sigue someter a análisis ciertas nociones que usa Cayetano en sus obras, sobre todo en el Comentario al De ente et essentiae de Tomás de Aquino. Nos referimos a los términos esse essentiae y esse actualis existentiae. Dos expresiones que han pasado al acervo tomista e incluso han sido mencionadas por pensadores contemporáneos de la talla de Martin Heidegger al momento de analizar el pensamiento de la Edad Media $^{2}$. Asimismo, a partir del análisis de algunos textos de Aristóteles y Tomás, podremos detectar si el Cardenal pudo haberse basado en alguno de ellos para utilizar los términos de marras. También pretendemos mostrar cómo el recurso a dichas nociones podría haber llevado a Tomás de Vio a ignorar o a prescindir del auténtico sentido del esse tomasiano. Luego, y sobre la base de los trabajos de reconocidos estudiosos, indagaremos acerca del origen de las expresiones esse essentiae y esse actualis existentiae. Por último, realizaremos algunas consideraciones centradas, sobre todo, en las consecuencias de la incorporación de dichas nociones para el pensamiento del comentador de Gaeta.

\section{El vocabulario de Cayetano en torno al ens}

En los textos de nuestro autor existen numerosas expresiones que merecen una atención particular al momento de entender su noción de ente. Desglosemos, pues, algunas de éstas para luego mostrar si existe o no algún tipo de interrelación entre ellas.

La primera de las expresiones es la de esse actualis existentiae. El Cardenal, al comentar el De ente et essentia, sostiene que ente (ens) es lo que tiene ser (habens esse) ${ }^{3}$; explica que el nombre ente se toma del ser mismo (ipsum

[2] Heidegger, Martin. Carta sobre el humanismo, trad. Helena Cortés y Arturo Leyte, Madrid, Ed. Alianza, 2000, pp. 33 y 35.

[3] "Circa minorem primae rationis nota, quod ens, ut infra dicetur, significat id quod habet esse". Cayetano, Tomás de Vio O.P. Comentaria in De ente et essentia D. Thomae Aquinatis, Roma, Edición H. Laurent, Marietti, 1934, p. 80. 
esse $)^{4}$ por el que la cosa es. Hasta aquí no parecería haber ningún tipo de incompatibilidad con la doctrina del Aquinate. Empero, después añade Cayetano que esse es aquello por lo que la cosa es o existe en la naturaleza de las cosas, o sea su existencia actual $^{5}$, igualando el ser a la existencia concreta. Este es uno de los puntos en donde el comentarista introduce una llamativa diferencia con el Aquinate en la noción de esse.

De acuerdo con lo antedicho, pareciera que Cayetano no concibe la noción de actus essendi tal como la entendió Tomás de Aquino ${ }^{6}$, porque aquél identifica el esse o actus essendi con la existencia actual o esse actualis existentiae, considerándolo como una realidad distinta de la esencia real de la criatu$\mathrm{ra}^{7}$. Por tanto, para nuestro autor el ente sería un compuesto de dos cosas distintas: la essentia y el esse ${ }^{8}$. Entonces, Cayetano no sólo cosifica el esse, sino que sostiene que éste sería la última actualidad que un ente obtiene como resultado de ser producido por una causa eficiente. Sin embargo, nada más alejado de la letras de Santo Tomás, para quien el esse no es una cosa sino un acto por el que cada sustancia es un ser. Explica Tomás de Vio:

[4] "Sed in Entis nomine duo aspici possunt, scilicet id a quo nomen Entis sumitur, scilicet ipsum esse, quo res est; et id ad quod nomen entis impositum est, scilicet id quod est". Cayetano, Tomás de Vio. Comentaria in De ente et essentia, p. 87.

[5] "In homine enim est considerare materiam in qua recipitur eius forma, et formam ipsam, quae est illius materiae actus, et essentiam humanam, quae nec est materia nec forma, et esse actualis existentiae, quo homo formaliter existit in rerum natura: unde fit, ut in istis substantiis duae compositiones pertinentes ad genus substantiae reperiantur". Cayetano, Tomás de Vio. Comentaria in De ente et essentia, p.139.

[6] A fin de ver directamente la letra de Santo Tomás, se pueden consultar, entre otros, los siguientes textos tomasianos: In IV Metaph. II: "Esse enim rei quamvis sit aliud ab eius essentia, non tamen est intelligendum quod sit aliquod superadditum ad modum accidentis sed quasi constituitur per principia essentiae"; De Pot., VII, II ad 9: "hoc quod dico esse est actualitas omnium actuum, et propter hoc est perfectio omnium perfectionum. Nec intelligendum est, quod ei quod dico esse aliquid addatur quod sit eo formalius, ipsum determinans, sicut actus potentiam: esse enim quod huiusmodi est, est aliud secundum essentiam ab eo cui additur determinandum. Nihil autem potest addi ad esse quod sit extraneum ab ipso, cum ab eo nihil sit extraneum nisi non ens, quod non potest esse nec forma nec materia. Unde non sic determinatur esse per aliud sicut potentia per actum, sed magis sicut actus per potentiam"; De Pot., V, IV ad 3: "esse substantiae est enim actus essentiae [...] non est pars essentiae [...]". Para precisar aún más esta noción pueden confrontarse otros muchos textos de Santo Tomás: II, 54, 3; De subst. separ., 8; De spir. creat., a. I c, etc. También se puede consultar el completo estudio de Fabro, Cornelio. Tomismo e Pensiero Moderno, Roma, Pontificia Università Lateranense, 1969, pp. 110-113. Allí se citan muchos más textos del Angélico referidos al esse.

[7] "Quoad secundum, opinio S. Thomae ab eo posita in II contra Gentiles, cap. LII, est quod in omni creatura quidditas et eius esse actualis existentiae distinguuntur realiter" [...]. Cayetano, Tomás de Vio O.P. Comentaria in De ente et essentia, p. 143.

[8] "S. Thomas autem ex fundamentis in dubitatione praecedenti positis opinatur intelligentias et quamlibet creaturam esse compositas ex actu et potentia, sicut ex duabus rebus distinctis realiter, esse scilicet et essentia”. Cayetano, Tomás de Vio O.P. Comentaria in De ente et essentia, p. 161.

THÉMATA. Revista de Filosofía, Nº49 enero-junio (2014) pp.: 235-254

doi: 10.12795/themata.2014.i49.13 
“[...] siendo el ser la actualidad última de una cosa, y por ser lo último en generación lo primero en intención, ser se hallará en el género de sustancia como principio formal último de la sustancia misma; porque, precisamente, algo se coloca en el género de sustancia porque es capaz de ser sustancial [...]"'.

$\mathrm{Al}$ afirmar lo anterior, Cayetano estaría restringiendo el esse a la categoría en la cual está el esse; así el ser se reduciría a la sustancia. Sin dudas, ésta puede ser una posición filosóficamente sostenible, pero ciertamente no es la del Aquinate: "según Santo Tomás -escribe Gilson-, el ipsum esse de la sustancia no es reductible a la sustancia, éste es el acto que hace de la sustancia un ente. Como todo habens esse, la sustancia es el receptor de esto que hace de ella un ente" 10 .

Estas desviaciones ya fueron notadas -antes que por los estudiosos contemporáneos- por otro gran comentador del Aquinate, Domingo Bañez. A este autor le llama poderosamente la atención la insistencia de Cayetano en identificar el acto de ser tomista con el ser real que el sujeto adquiere al término de la generación. Para Bañez, el esse tomista no es el actus ultimus en el sentido de la actualidad obtenida finalmente por el sujeto en su devenir, sino, más bien, su actus primus, aquel sin el cual el sujeto del devenir no sería el mismo ser y sin el cual ni siquiera habría devenir. García Cuadrado en su estudio sobre Bañez, ejemplifica la crítica del dominico español diciendo que el acto de ser de Santo Tomás no es el que hace que el embrión llegue al término de su evolución biológica, sino que es el acto que hace que el mismo embrión exista ${ }^{11}$. Por tanto, cuando el Angélico sostiene que el esse es el acto primero y último, no se refiere a que sea último en el tiempo, sino que es último porque es acto supremo, allende el cual no existe otro ${ }^{12}$. Por el contrario, de acuerdo con los textos antes citados, Cayetano no lo entendió de ese modo.

[9] "[...] cum esse sit ultima actualitas rei et ultimum in generatione sit primum in intentione, esse erit in genere substantiae ut principium formale ultimatum ipsius substantiae; per hoc enim res reponitur in genere substantiae, quia est capax esse substantialis, etenim differentiae in omnibus generibus, ut infra declarabitur, sumuntur ab ordinc ad ipsum esse”. Cayetano, Tomás de Vio O.P. Comentaria in De ente et essentia, p. 159.

[10] Gilson, Étienne, Cajetán et l’humanisme théologique, Archives d'histoire doctrinale et littéraire du Moyen Age 30, 1955, p. 119.

[11] García Cuadrado, José A. La luz del intelecto agente. Estudio desde la metafísica de Bañez, Pamplona, ed. EUNSA, 1998, pp. 65-66.

[12] Bañez, Domingo. Scholastica commenttaria in Primam Partem Summae Theologicae D. Thomae Aquinalis, Madrid-Valencia, ed. Luis Urbano, t. I, 1934, ad 1, 3, 4; p. 142: "Cajetanum etiam De ente et essentia, c. 5, q. 11, ad 8 argumentum ait, existentiam substantiae esse substantiam [...]", etc. - p. 145: "Et idcirco non placet mihi explicatio Caietani ubi supra, videlicet, quod proptera dicatur existentia ultima actualitas rei quia est ultimum in generatione. Certe hic modus loquendi quod ipsum esse sit ultima actualitas rei, raro invenitur apud Divum Thomam. Inventes in quaestione unies De anima, art. 6 , ad $2 \mathrm{~m}$, ubi inquit, quod ipsum esse est actus ultimus, qui partieipabilis est ab omnibus. In quo loco, si sequentia legeris, intelliges quomodo ipsum esse sit actus ultimus, nimirum supremus excellentissimus, qui omnes etiam alios actus perficit".

THÉMATA. Revista de Filosofía, No 49 enero-junio (2014) pp.: 235-254

doi: 10.12795/themata.2014.i49.13 
Además de la expresión esse actualis existentiae, que recién se explicó, Cayetano incorpora otra: esse essentiae (ser de la esencia) o su equivalente esse quiditativum (ser quiditativo). Y estrechamente relacionado con estas dos se ubica la división de Cayetano entre ens nominaliter y ens participialiter o verbaliter, o el ente como acto signado y como acto ejercido. Así el esse essentiae sería el ens nominaliter, mientras que el esse existentiae sería el ens participialiter o ens verbaliter. Dice Cayetano al glosar la Suma de Teología:

“[...] en efecto, es manifiesto que el ser puede tomarse de dos maneras, a saber, como acto ejercido de la misma existencia y [como acto signado] por modo de la quididad. Y lo que como ejerce la existencia, agrega sobre si misma como lo que es. Y por consecuencia, como objeto del intelecto, es abstracto [...]"13.

Sabemos que el término ens (ente) puede entenderse como nombre o como verbo. Como nombre o sustantivo significa un ente, lo que es, cualquiera de las cosas que son, lo que tiene ser. Como verbo o participio significa el hecho mismo que una cosa sea, lo que efectivamente ejerce el acto de ser, lo que está siendo. Así como la palabra estudiante, si se toma como nombre, se aplica a aquella persona cuyo acto propio es el estudiar, aunque de hecho no lo esté haciendo. Así, tomada como participio, se refiere sólo al que de hecho está estudiando; al igual que por viviente puede entenderse tanto aquello cuyo acto propio es vivir como aquello que vive en acto. A partir de estas distinciones, Cayetano le da ciertas características específicas al ente, según se lo tome como nombre o como participio.

El ens nominaliter es llamado lo que es o puede ser, pero no se quiere expresar con ello la existencia de hecho, por ello se habla de connotación del esse in actu signato (el ser en acto expresado). Este es el esse essentiae o esse quiditativum, el cual ya tiene una cierta realidad: la esencia o naturaleza universal, v.gr.: hombre.

Por el contrario, el ens participialiter dice lo que de hecho es o connota el esse in actu exercito (el ser en acto ejercido) lo que sólo puede ser afirmado hablando de la experiencia, dado que el hecho es únicamente objeto de experiencia, v.gr.: el hombre concreto.

Dado el conocimiento que Tomás de Vio tenía tanto de Aristóteles como de Santo Tomás, podría pensarse que el antecedente de las expresiones ante-

[13] “[...] iam enim patet quod esse dupliciter sumi potest: scilicet in actu exercito ipsius existentiae; et per modum quidditatis. Et quod ut exercet existentiam, addit supra seipsum ut quod quid est. Et consecuenter ut obiectum intellectus, est abstractius [...]" Cayetano, Tomás de Vio O.P. en Sancti Thomae Aquinatis, Summa Theologica cum comentario Cardenali Caietani, de la Opera Omnia, Romae, ed. Leonina, 1883. I, q. 82, a. 3; XV, p. 301. La distinción entre acto signado y acto ejercido también puede ser consultada, hasta lo que sabemos, en otras dos obras del mismo autor: Comentaria in De ente et essentia, p. 87 y De nominum analogia. Texto latino según edición Zammit O.P. (con notas de Zammit), trad. y notas de Guido Soaje Ramos, Mendoza, Universidad Nacional de Cuyo, Instituto de Filosofía, 1949, p.118.

THÉMATA. Revista de Filosofía, Nº49 enero-junio (2014) pp.: 235-254

doi: 10.12795/themata.2014.i49.13 
dichas empleadas por el Cardenal estaría sustentado en la letra de alguno de aquellos pensadores. En relación al Estagirita, podría suponerse que Cayetano se habría inspirado en la conocida distinción aristotélica entre definición y demostración para hablar de esse essentiae y esse existentiae. Con respecto al Aquinate, son muchos los pasajes que podrían señalarse, ya que lo que hace el dominico de Gaeta es justamente comentar la obra del Angélico. Sin embargo, creemos que en su glosa al De ente et Essentia de su maestro es donde Cayetano explicita las distinciones mencionadas. Así, en el capítulo V, cuestión X de dicho opúsculo, el comentador italiano trae a colación un texto del Aquinate en el que pretendería asentar su argumentación y de allí empezar a hablar de esse actualis existentiae en lugar de esse o actus essendi.

Siguiendo esta línea argumental, sería interesante acometer un estudio de los textos de Aristóteles y de Santo Tomás a fin de detectar si existe algún asidero en ellos para que Cayetano introduzca las expresiones esse essentiae y/o esse actualis existentiae.

\section{Esencia y existencia en Aristóteles y en Cayetano}

En el Libro II Capítulo VII de los Segundos Analíticos, el filósofo griego expone las diferencias entre la definición y la demostración:

\footnotetext{
"Pues la definición lo es del qué es y de la sustancia; las demostraciones, en cambio, parecen presuponer y dar por sentado todas el qué es, v.g.: las matemáticas [presuponen] qué es la sustancia y qué es lo impar, y las demás [ciencias], de manera semejante. Además, toda demostración demuestra algo acerca de algo, v.g.: que es o que no es, en cambio en la definición no se predica nada de otra cosa distinta, v.g.: ni animal acerca de bipedo ni esto acerca de animal, tampoco figura acerca de superficie: pues la superficie no es una figura, ni la figura una superficie. Además, una cosa es demostrar el qué es y otra [el hecho de] que es. Así pues, la definición indica qué es [tal cosa], la demostración, en cambio, indica que tal cosa es o no es con relación a tal otra" ${ }^{14}$.
}

Lo que quiere decir Aristóteles ${ }^{15}$, entonces, es que la esencia será objeto de definición, sea de un ente físico como el hombre o de uno matemático como el triángulo; mientras que la existencia será objeto de demostración, i.e, de que algo es o que no es. Por ello la definición muestra qué es una cosa, pero no que esta cosa exista o no. Y unas líneas más adelante sostiene el Estagirita: "tampoco [se da] el qué es sin el hecho de que sea: pues es imposible saber qué es

[14] Aristóteles. Analíticos Posteriores, 90b 30-91a 1, Madrid, Ed. Gredos, 2007, trad. Miguel Candel Sanmartin. Hemos preferido el uso del término sustancia en lugar de entidad; éste último es el que utiliza el traductor para ousía. Las cursivas y las reposiciones son del texto original, lo mismo en el resto de las citas.

[15] Aquí intentamos seguir parte del razonamiento de Echauri, Raúl, Esencia y existencia en Aristóteles, Anuario Filosófico, 8, 1975, pp. 119-129.

THÉMATA. Revista de Filosofía, Nº49 enero-junio (2014) pp.: 235-254

doi: 10.12795/themata.2014.i49.13 
[una cosa] ignorando si es"16. En otras palabras, no hay esencia sin existencia o la definición de una cosa real supone la existencia de lo definido.

Por ello Aristóteles afirmará que si bien la definición indica una cosa única, "qué es el hombre y [el hecho] que el hombre sea son cosas distintas"17. Por lo general se entiende que el Filósofo acá se está refiriendo a la conocida distinción entre esencia y existencia, es decir, al contenido inteligible de un ente y a la realidad fáctica de ese mismo ente ${ }^{18}$.

Ahora bien, itales distinciones podrían aplicarse a las usadas por Cayetano? ¿Podría decirse que la esencia y la existencia aristotélica se equiparan con el esse essentiae y el esse actualis existentiae que postula el Cardenal? Por nuestra parte, creemos que no hay una correspondencia total, puesto que entre el binomio de conceptos mencionados existen importantes diferencias.

Por un lado, la noción esse essentiae indica algo que puede llegar a ser o una realidad bajo un aspecto estático, y el esse actualis existentiae refiere a la existencia actual o a una realidad dinámica. Sin embargo, la esencia y la existencia aristotélica no indican un ente posible por un lado y otro actual por el otro, sino la esencia real de una cosa y la existencia efectiva de la misma cosa, pero en el mismo ente. Para el Estagirita la esencia es lo que la cosa actual es, mientras que para el fraile de Gaeta será la pura posibilidad de un ente que aún no tiene existencia actual. Empero, podría decirse que se da una coincidencia entre la existencia de Aristóteles y el esse actualis existentiae de Cayetano, en cuanto ambos refieren al objeto propio de la experiencia.

Según lo anterior, podría seguirse que la terminología que usa Cayetano -esse essentiae y esse actualis existentiae - no es fruto de la lectura directa del maestro del Liceo o no se deduce inmediatamente de sus escritos. Más aún, si se consultan los comentarios que Tomás de Vio realiza a los pasajes aludidos del Libro II, Capítulo VII de los Segundos Analíticos de Aristóteles ${ }^{19}$, se deja ver claramente que en ningún momento hace alusión a estas expresiones.

Veamos a continuación si las distinciones de nuestro autor se asientan o no en la letra del Aquinate. En vistas a que la tarea de Cayetano se centra sobre todo en comentar a Tomás de Aquino y dado el lugar preponderante que ocupa éste último en la obra del Cardenal, nos detendremos en el análisis de los pasajes tomasianos con mucho más detalle de lo que lo hicimos con los del Estagirita.

[16] Aristóteles. Analíticos Posteriores, 93a 19-22.

[17] Aristóteles. Analíticos Posteriores, 92b 8-10.

[18] Cfr. Echauri, Raúl, Esencia y existencia en Aristóteles, p. 120.

[19] Cfr. Cayetano, Tomás de Vio O.P. Commentaria in Posteriora Analytica Aristotelis. Textus ex editione Lugdunensi (1579) exerptus et a E. Babin et W. Baumgaertner. Exaratus et emendatus. Liber II (1951), pp. 77-115.

THÉMATA. Revista de Filosofía, Nº49 enero-junio (2014) pp.: 235-254 doi: 10.12795/themata.2014.i49.13 


\section{La letra tomasiana: Contra Gentiles II, 54}

Para atestiguar que Santo Tomás habla de esse actualis existentiae, en su Comentario al De ente et essentia Cayetano no sólo se basa en la letra del opúsculo tomasiano, sino que trae a colación un pasaje de otra de las obras del Aquinate. Nos referimos al Libro II, Capítulo LIV, de la Suma Contra Gentiles.

Antes de pasar al análisis del fragmento aludido, vale aclarar que el comentario de Cayetano al De ente et essentia fue escrito fundamentalmente con la intención de combatir los errores de Escoto y de sus discípulos, en especial de Antonio Trombeta - colega y adversario del Cardenal en la Universidad de Padua-. En este sentido, casi todo el desarrollo del comentario se constituye en una permanente respuesta desde el tomismo a las variadas y agudas confutaciones escotistas.

Ahora bien, Cayetano alude a diferentes distinciones a partir de un fragmento del De ente et essentia. Dice allí Tomás de Aquino en referencia a las sustancias separadas:

"Tales sustancias, por consiguiente, aunque sean sólo formas sin materia, sin embargo, no hay en ellas una simplicidad absoluta, de modo que sean acto puro, sino que tienen mezcla de potencia. Y esto es patente del modo siguiente. En efecto, todo lo que no pertenece al concepto de esencia, o de quididad, es lo que proviene de fuera y se compone con la esencia, porque ninguna esencia puede ser entendida sin lo que es parte suya. Ahora bien, toda esencia o quididad puede ser entendida sin que se entienda algo de su ser; puedo, en efecto, entender qué es el hombre o el fénix, $y$, sin embargo ignorar si tiene ser en la naturaleza de las cosas. Por consiguiente, es patente que el ser es distinto de la esencia o quididad" ${ }^{20}$.

A partir de este texto, Cayetano explica que según Tomás de Aquino las sustancias separadas están compuestas de ser y de esencia, pero antes de probar esto advierte el Cardenal:

“[...] se debe notar que en las sustancias materiales hay cuatro [cosas] realmente distintas, a saber: materia, forma, esencia compuesta de ellas, y existencia. En efecto, en el hombre hay que considerar la materia en que se recibe su forma, la forma misma, que es acto de tal materia, la esencia humana que no es ni la materia ni la forma, y el ser de la

[20] Tomás de Aquino. El ente y la esencia, trad., estudio preliminar y notas de Eudaldo Forment, Pamplona, ed. EUNSA, 2006, p. 285. Aquí el texto completo de Santo Tomás: "Huiusmodi ergo substantiae quamvis sint formae sine materia, non tamen in eis est omnimoda simplicitas, nec sunt actus puri, sed habent permixtionem potentiae, et hoc sic patet: Quidquid enim non est de intellectu essentiae vel quidditatis, hoc est adveniens extra, et faciens compositionem cum essentia; quia nulla essentia sine his quae sunt partes essentiae intelligi potest. Omnis autem essentia vel quidditas intelligi potest sine hoc, quod aliquid intelligatur de suo esse facto; possum enim intelligere quid est homo vel phœnix, et tamen ignorare an esse habeant in rerum natura: ergo patet quod esse est aliud ab essentia vel quidditate".

THÉMATA. Revista de Filosofía, Nº49 enero-junio (2014) pp.: 235-254

doi: 10.12795/themata.2014.i49.13 
existencia actual por el que el hombre existe formalmente en la naturaleza de las cosas; de lo cual resulta que en tales sustancias se hallan dos composiciones, pertenecientes al género de sustancia, de las cuales la primera es la de materia y forma; la segunda, la de esencia y existencia, composición que se llama de ser y esencia"21.

Tal como lo mencionamos anteriormente -y en este pasaje se deja ver nuevamente-, Cayetano identifica el esse tomasiano con la existencia actual o concreta de un ente. Asimismo, insiste en cosificar el ser tomasiano, cuando para Santo Tomás el ser y la esencia son dos principios que componen el ente, y no dos cosas, tal como afirma Cayetano ${ }^{22}$.

En este punto es importante recordar que en la doctrina tomasiana no se llega al esse como se llega al ente o como se concibe la esencia,

"porque [sostiene Fabro] el ser no es un resultado, no es un punto de llegada o sólo de partida: el ser es el prius absoluto tanto en el ente que él sostiene como en el espíritu. El ser no es un concepto, sino el acto de toda realidad"23.

Hecha esta aclaración continuemos con el hilo de la argumentación cayetaniana. Nuestro autor, luego de la advertencia sobre la doble composición de las sustancia materiales -materia-forma, esencia-existencia-, pasa a enumerar las similitudes y diferencias entre ambas composiciones. Lo que nos interesa destacar es la quinta diferencia, ya que es allí donde Cayetano alude al texto tomasiano de la Contra Gentiles II, LIV ${ }^{24}$. Antes de citar el comentario de Tomás de Vio, veamos la letra del Aquinate:

"Tercero, porque la forma no es el ser, aunque entre ambos haya un cierto orden; pues la forma es comparada con el mismo ser, como la luz es comparada con la iluminación o la blancura con el ser blanco. Además, porque el ser con respecto a la forma es acto. Por eso, en los compuestos de materia y forma, se dice que la forma es el principio de ser, porque

[21] "[...] in substantiis materialibus inveniri quatuor realiter distincta; scilicet materiam, formam, essentiam compositam ex eis, et existentiam. In homine enim est considerare materiam in qua recipitur eius forma, et formam ipsam, quae est illius materiae actus, et essentiam humanam, quae nec est materia nec forma, et esse actualis existentiae, quo homo formaliter existit in rerum natura: unde fit, ut in istis substantiis duae compositiones pertinentes ad genus substantiae reperiantur. Quarum prima est ex materia et forma ; secunda est ex essentia et existentia, quae vocatur compositio ex esse et essentia". Cayetano, Tomás de Vio O.P. Comentaria in De ente et Essentia, p.139. En la traducción reponemos la palabra cosas, porque posteriormente Cayetano se referirá al ser y a la esencia como dos cosas distintas. Cfr. Cayetano, Tomás de Vio O.P. Comentaria in De ente et Essentia, p. 161. El texto completo fue citado en la nota 8 del presente artículo.

[22] "S. Thomas autem ex fundamentis in dubitatione praecedenti positis opinatur intelligentias et quamlibet creaturam esse compositas ex actu et potentia, sicut ex duabus rebus distinctis realiter, esse scilicet et essentia”. Cayetano, Tomás de Vio O.P. Comentaria in De ente et essentia, p. 161.

[23] Fabro, Cornelio. Dall'essere al esistente, Brescia, Ed. Morcelliana 1957, pp. 66-67.

[24] Cfr. Gilson, Étienne, Cajétan et l'existence, Tijdschrift voor Philosophie 15, 1953, p. 274 y Reilly, John P., Cajetan: essentialist or existentialist?, The New Scholasticism 41, 1967, p. 198. Ambos autores, uno para criticar y otro para defender a Cayetano, hacen foco en el pasaje tomasiano que cita el Cardenal.

THÉMATA. Revista de Filosofía, Nº49 enero-junio (2014) pp.: 235-254

doi: 10.12795/themata.2014.i49.13 
es el complemento de la substancia, cuyo acto es el mismo ser; así, la diafanidad es para el aire el principio de lucir, porque lo hace sujeto propio de la luz"25.

\section{A continuación reproducimos la paráfrasis al texto tomasiano por parte de Cayetano:}

"Pues tal proporción de la forma al existir actual es la misma que de la diafanidad a la luz, porque al modo que el aire, en cuanto aire, no es capaz de luz, sino que conviene que sea informado en sí mismo por la diafanidad, para que así llegue a haber un receptor apropiado para la luz, que no lo son ni el aire ni la diafanidad sino el aire diáfano, por eso éste es el primeramente luminoso, aunque secundariamente tanto el aire como la diafanidad carezcan de luz; así también, en el caso propuesto, la materia sola no es capaz de existencia; porque el acto ha de ser recibido en la potencia apropiada, sino que la forma ha de recibirse en la materia para que resulte un receptor apropiado de la existencia, que no lo son ni la materia ni la forma, sino el compuesto de ellas" ${ }^{26}$.

Varios puntos son merecedores de atención en estos textos. En primer lugar, la manera en que Cayetano equipara el esse del Aquinate al esse actuale. A primera vista podría parecer que son términos convertibles, y que lo único que logra el Cardenal con el agregado actuale es reforzar el carácter de acto que posee el esse frente a la forma, la cual hace las veces de principio potencial. Sin embargo creemos que no es éste el caso, el comentador a renglón seguido directamente remplaza la palabra esse por la de existentia, y luego avanza en su glosa haciendo uso exclusivo de ésta última. Es conveniente insistir en este punto, en tanto que todo lo que digamos sobre él ayudará a precisar con exactitud el significado de la noción de esse o existentia para Cayetano.

En segundo lugar, si se remplaza esse por existentia, tal como lo hace Cayetano, la argumentación tomasiana pierde fuerza. Esto es, si Santo Tomás en el texto aludido sostiene que la forma y el ser son comparables a la relación que se da entre la luminosidad y la luz, de modo evidente le está dando al esse un primado metafísico que de ninguna manera posee la noción de existencia.

[25] "Tertio, quia nec forma est ipsum esse, sed se habent secundum ordinem: comparatur enim forma ad ipsum esse sicut lux ad lucere, vel albedo ad album esse. Deinde quia ad ipsam etiam formam comparatur ipsum esse ut actus. Per hoc enim in compositis ex materia et forma dicitur forma esse principium essendi, quia est complementum substantiae, cuius actus est ipsum esse: sicut diaphanum est aeri principium lucendi quia facit eum proprium subiectum luminis". Cfr. Silvestre de Ferrara. in Sancti Thomae Aquinatis, Summa Contra Gentiles (cum comentario Silvestre de Ferrara), vol. XIII de la Opera Omnia, Romae, ed. Leonina, 1883, Lib. II, Cap. LIV. p. 392. Tomás de Aquino. In II Sent., 3, 1, 1, Resp.

[26] "Est enim proportio formae ad esse actuale, sicut proportio diaphaneitatis ad lumen; forma siquidem recipit exsistentiam et causat eam, sicut diaphaneitas lumen. Sicut namque aër in eo, quod aër non est capax luminis, sed oportet ipsum diaphaneitate informari, ut proprium receptivum luminis fiat: ideoque neque aër nec diaphaneitas, sed aër diaphanus est qui primo luminosus est, licet secundario tam aër quam diaphaneitas lumine clareat; ita in proposito materia sola non est capax existentiae, quia actus in propria suscipi debet potentia; sed oportet in ipsa formam recipi, ut proprium receptivum existentiae flat, non materia nec forma sed compositum ex eis". Cayetano, Tomás de Vio O.P. Comentaria in De ente et essentia, p. 140.

THÉMATA. Revista de Filosofía, Nº49 enero-junio (2014) pp.: 235-254

doi: 10.12795/themata.2014.i49.13 
Para Cayetano, el ser (la existencia) es lo último en generación, por el contrario, para el Aquinate es lo anterior y más simple que cualquiera de las perfecciones de las cosas existentes. Por ello, el mismo Tomás de Aquino afirma que el esse no se compara a las demás cosas como el recipiente a lo recibido sino como lo recibido al recipiente ${ }^{27}$. Sería inexacto, desde el pensamiento del Aquinate, considerar la existencia como el último fundamento de lo real o creer que de ella provienen todas las perfecciones que se encuentran en las cosas. Según el Doctor Común, el esse es el que posee un carácter de fundamento ${ }^{28}$ y de preeminencia $^{29}$ sobre el resto de las perfecciones, mas no la existencia. Por ello, la metafísica tomasiana no entiende el esse como la realización de la esencia, es decir como existencia. Ésta indica el hecho de la realidad en acto y el paso del estado de posibilidad de la esencia a la realidad, paso que ha sido explicado como la posición fuera de la nada y fuera de las causas ${ }^{30}$. Si el ser es entendido como existencia, pierde valor metafísico, dado que se lo concebirá como un añadido extrínseco producto de una causalidad que hace real lo posible; en este contexto el ser pasará a entenderse como el complemento de la posibilidad ${ }^{31}$.

Estas son alguna de las dificultades que implica la lectura de Cayetano sobre el esse, la cual en el texto analizado se caracteriza por haber eclipsado dicha noción y en su lugar haber propuesto la de existentia como su reemplazo conceptual. Algo notable es que el Cardenal ha usado la misma terminología que sus adversarios para entrar en la discusión. Probablemente lo hizo para poder ser entendido tanto por tomistas como por escotistas, o quizá porque nunca llegó a comprender acabadamente la noción de actus essendi, o tal vez porque no creía que dicha noción fuera propia del ámbito filosófico puesto que no estaba contenida en la metafísica de Aristóteles. Esta última motivación no era menor ya que en la época y contexto de Cayetano el Estagirita era la medida de la filosofía.

Lo cierto es que nuestro autor usa el vocablo existentia en lugar de esse y se lo atribuye a Santo Tomás, y aunque para algunos defensores de la postura cayetaniana este cambio de lenguaje no comporte dificultades ${ }^{32}$, por nuestra parte creemos que -tal como hemos intentado probar- son numerosas y profundas las consecuencias doctrinales que se desprenden de intentar remplazar el esse tomasiano por la existentia.

[27] Cfr. Tomás de Aquino. In S. Th., q. 4 a. 1 ad 3.

[28] Cfr. Tomás de Aquino. In I Sent. d. 2, q.1, a. 1. ad 2.

[29] Cfr. Tomás de Aquino. In S. Th., I-II q. 2, a. 5 ad 2.

[30] Fabro, Cornelio. Tomismo e Pensiero Moderno. p. 104.

[31] González, Ángel L. Ser y Participación. Estudio sobre la cuarta vía de Tomás de Aquino, Pamplona, Ed. EUNSA, 2001, p. 116.

[32] Reilly, Jonh P., Cajetan: essentialist or existentialist?, p. 192.

THÉMATA. Revista de Filosofía, Nº 49 enero-junio (2014) pp.: 235-254

doi: 10.12795/themata.2014.i49.13 
Asimismo, a fin de apreciar con mayor nitidez las mencionadas consecuencias, creemos que será provechoso estudiar brevemente la génesis de las expresiones "ser de la esencia" y "ser de la existencia actual".

\section{El origen de las expresiones esse essentiae y esse actualis existentiae}

Según la autorizada opinión de algunos estudiosos contemporáneos, el binomio esse essentiae y esse actualis existentiae se remontaría antes bien a Avicena. Al respecto dice Fabro:

"La terminología de esse essentiae y esse existentiae, recordada por Heidegger, no es de Santo Tomás, sino de su adversario y de la fuente de Scoto que es Enrique de Gante: en la concepción escotista, y en general en el extrinsecismo aviceniano asumido por la mayor parte de la Escolástica, el momento decisivo de la realidad de lo real es el pasaje de la posibilidad a la realidad y esto se resuelve en el pasaje de la esencia posible (esse essentiae) a la esencia realizada (esse existentiae)"33.

Asimismo, Gilson, en consonancia con Fabro, cree que la expresión esse essentiae es deudora de la distinción aviceniana del triple estado de la esencia, a saber, en la mente, en las cosas y considerada en sí misma. De este último modo es como la esencia se daría si no hubiera ni mentes ni cosas. En tal sentido, el medievalista francés estima que la esencia en este tercer estado se correspondería con las ideas platónicas ${ }^{34}$. Explica Gilson:

"Lo que ahora estamos presenciando, en la filosofía de Avicena, es la aparición de un curioso tipo de ser, el esse essentiae de Enrique de Gante y de tantos otros filósofos escolásticos. No es un ser de existencia (esse existentiae), aunque es un cierto tipo de ser, a saber: aquel que pertenece a la esencia como tal, independientemente del hecho de que esté o no esté actualizado en algún sujeto cognoscente o en alguna cosa individualmente existente" 35 .

Para el Doctor Solemne, la raíz última de las cosas creadas es su esencia, la cual se identifica con una idea divina que tiene un ser propio, y a este ser propio se lo denomina esse essentiae ${ }^{36}$. Al parecer, lo que hizo Enrique de Gante fue reforzar la enseñanza de Egidio Romano, para el cual la esencia es una realidad eterna que no puede ser creada. Dios sería la causa eficiente de la cosa, pero sólo de su existencia, mientras que de la esencia sería su causa ejemplar ${ }^{37}$.

[33] Fabro, Cornelio. Dall'essere all'esistente, p. 419. Las cursivas son del autor.

[34] Gilson, Étienne. El ser y los filósofos, Pamplona, Ed. EUNSA, 2005, pp. 109-110.

[35] Gilson, Étienne. El ser y los filósofos, p.110. De la misma opinión son: Fernand Van Steenberghen, Le problème de l'existence de Dieu dans le De ente et essentia de Saint Thomas d'Aquin, Mélanges de Fhellinck, vol. II, Lovaina, 1951, p. 848 y Courtine, Jean-Francois. Suarez et le systeme de la métaphysique, Paris, Ed. PUF, 1990, p.183.

[36] Cfr. Gilson, Étienne. History of Christian Philosophy in the Middle Ages, New York, Ed. Random House, 1955, p. 424.

[37] Cfr. García Cuadrado, José A. La luz del intelecto agente, p. 57.

THÉMATA. Revista de Filosofía, Nº49 enero-junio (2014) pp.: 235-254

doi: 10.12795/themata.2014.i49.13 
Entonces, Cayetano, al tomar el léxico esse essentiae, casi indefectiblemente estaría asumiendo los planteos y problemáticas que este vocabulario suscita: en este caso, que el ser sería una nota o accidente de la esencia, y que ésta tendría un cierto tipo de ser antes de pasar a la existencia concreta ${ }^{38}$. Lo sorprendente es que el comentador de Gaeta no toma este vocabulario para criticarlo sino que lo incorpora como propio, y lo que es más audaz aún, se lo atribuye al mismo Santo Tomás, pasando por alto lo que el mismo Aquinate había dicho:

\begin{abstract}
“[...] esto que llamo ser es lo más perfecto de todo. En efecto, es evidente que el acto es siempre superior a la potencia. Pero ninguna forma puede ser considerada en acto sino en cuanto se la pone siendo. Pues la humanidad o la igneidad pueden considerarse como existiendo en la potencia de la materia o en la virtualidad del agente o también en el entendimiento, pero sólo se dan existentes en acto por el hecho de que tengan ser. Luego es evidente que esto que llamo ser es la actualidad de todos los actos y, por lo mismo, la perfección de todas las perfecciones" ${ }^{39}$.
\end{abstract}

Por otro lado, Ralph McInerny en uno de sus últimos libros, Praeambula Fidei: Thomism and the God of the Philosophers, renueva la discusion en torno a las nociones usadas por Cayetano y emprende un embate contra la postura gilsoniana. El filósofo norteamericano explica que el Cardenal sólo usa una vez la frase esse actualis existentiae, y por esta única mención Gilson lo ha acusado de perder de vista lo que el Aquinate quería decir ${ }^{40}$.

Es verdad que, al comentar el De ente et essentia, el Cardenal utiliza en pocas ocasiones la expresión mencionada -aunque no una, como sostiene McInerny ${ }^{41}$, sin embargo dicho término se corresponde con otro ya explicado y también aludido por Cayetano en la misma obra, a saber, ens participialiter. Además, v.gr. en sus Comentarios a los Analíticos posteriores de Aristóteles ${ }^{42}$ y a la Suma de Teología, el Cardenal también emplea la expresión esse actualis existentiae ${ }^{43}$.

[38] Cfr. Prouvost, Géry. Thomas d’Aquin et le thomistes, París, Les Éditions du Cerf, 1996, p. 95.

[39] “[...] hoc quod dico esse est inter omnia perfectissimum: quod ex hoc patet quia actus est semper perfectio potentia. Quaelibet autem forma signata non intelligitur in actu nisi per hoc quod esse ponitur. Nam humanitas vel igneitas potest considerari ut in potentia materiae existens, vel ut in virtute agentis, aut etiam ut in intellectu: sed hoc quod habet esse, efficitur actu existens. Unde patet quod hoc quod dico esse est actualitas omnium actuum, et propter hoc est perfectio omnium perfectionum”. Tomás de Aquino, In De Pot., q. 7, a. 2 ad 9.

[40] Cfr. Mcinerny, Ralph. Praeambula Fidei: Thomism and the God of the Philosophers, Washington, The Catholic University of America Press, 2006, pp. 62-63.

[41] Mcinerny, Ralph. Praeambula Fidei, p. 63.

[42]Cayetano, Tomás de Vio, O.P. Commentaria in Posteriora Analytica Aristotelis. Textus ex editione Lugdunensi (1579) exerptus et a E. Babin et W. Baumgaertner. Exaratus et emendatus. Liber I (1950), Les editions de l’Univertité Laval, Faculté de Philosophie, Québec, pp. 11, 17 y Liber II (1951), p. 71.

[43] Cayetano, Tomás de Vio O.P. en Sancti Thomae Aquinatis, Summa Theologica cum comentario Cardenali Cayetani, de la Opera Omnia, Romae, ed. Leonina, 1883, I, q. 3. a. 5. p. 44; q. 28. a. 2.

THÉMATA. Revista de Filosofía, Nº49 enero-junio (2014) pp.: 235-254

doi: 10.12795/themata.2014.i49.13 
Leo Elder es otro importante tomista actual que cree que la distinción cayetaniana se aparta de la doctrina tomasiana. Este autor, en un trabajo reciente, sostiene que los términos esse essentiae y esse actualis existentiae no son para nada convenientes al lenguaje tomasiano y también remoza la tesis gilsoniana de que tal vocabulario tendría sus raíces en la influencia escotista y antes aún en Avicena ${ }^{44}$.

\section{Consideraciones finales}

Este estudio pretende ser un aporte para el análisis de algunos términos que maneja Cayetano en torno a la noción de ente, en concreto esse essentiae y esse actualis existentiae. Habida cuenta de que la labor de Cayetano se centró en comentar y difundir la enseñanza de Tomás de Aquino, resulta natural hacer un parangón entre los desarrollos doctrinales de ambos dominicos con respecto al uso de los términos antedichos. Y sobre esta comparación podemos hacer algunas reflexiones.

Es manifiesto que el comentarista de Gaeta emplea una terminología ajena a la de Santo Tomás. Aunque podría suponerse que lo hace para clarificar o para perfeccionar algunas cuestiones de la doctrina de su maestro que necesitaban salir a la luz o completarse. Sin embargo, por lo menos en este caso concreto, no se da así en tanto lo que logra Cayetano cuando hace uso de las expresiones esse essentiae y esse actualis existentiae es cambiar no sólo las palabras, sino también la enseñanza tomasiana sobre el acto de ser.

Esta alteración operada en la doctrina del Aquinate no resulta extraña en razón de que los términos que incorpora el Cardenal pertenecen a los oponentes de Tomás de Aquino, a saber, Duns Escoto y Trombeta. Pero si lo que pretende Cayetano es defender al Aquinate, resulta a lo menos paradójico que lo haga en el mismo campo conceptual y con los elementos de polémica que el Sutil y su discípulo habían propuesto.

Esta situación obliga a Cayetano a tomar y a desarrollar disquisiciones que se adecuen a las objeciones esgrimidas, en virtud de que, como recién mencionamos, está discutiendo con elementos y vocabulario escotista. Dicho de otro modo, no creemos que Santo Tomás hubiese aceptado que se reemplazara sin más la noción de esse por la de existentia. Este escollo con el que tropieza Cayetano produce en él una mezcla de elementos escotistas y tomistas. Y si bien no

p. 322; II, q. 27 a.2., p.223, 224, 225, 226, 227. Nuestra hipótesis es que en sus escritos Cayetano siempre utiliza la expresión esse actualis existentiae con un sentido similar al de sus comentarios al De ente et essentiae. Empero, demostrar esto merecería un estudio de cada lugar en el cual aparece el término en cuestión.

[44] Cfr. Elders, Leo, Cayetano, comentador de la Suma de teología de Santo Tomás, (2011). Disponible en: http://bibliotecadigital.uca.edu.ar/repositorio/ponencias/cayetano-comentadorsuma-teologia-tomas.pdf

THÉMATA. Revista de Filosofía, Nº49 enero-junio (2014) pp.: 235-254 doi: 10.12795/themata.2014.i49.13 
dudamos de las buenas intenciones del comentador italiano, los efectos de su posición frente a los problemas planteados han llevado la discusión por carriles ajenos a la doctrina del Doctor Común. Así las cosas, según nuestro juicio, la terminología utilizada por el Cardenal en la discusión no sólo es material sino formalmente escotista.

Cabe señalar, por otro lado, que cuando no se entiende el actus essendi como fundamento del ente, a lo máximo que se llega es a considerarlo como realización de la esencia. Esto puede haber sido uno de los motivos que condujeron a Cayetano a desfigurar o a perder el esse tomasiano, llevando a identificar el actus essendi con el esse actualis existentiae. En este sentido afirma Gilson:

"Para que Cayetano haya aceptado argumentar en términos de ser de existencia actual, e incluso sostenido que Santo Tomás había hablado de ello en C.G. II, 52, es necesario que él también haya dejado escapar o eliminado la noción misma de esse"45.

Tal como venimos señalando, el entender el esse como lo que está fuera de la nada y fuera de las causas es concederle demasiado a los detractores de la distinción real entre essentia y esse. El esse no es la realización de la esencia sino que es un acto intensivo ${ }^{46}$ que implica grados de ser; mientras que, contrariamente, el existir indica el aspecto más superficial y en cierto sentido unívoco de los entes, ya que es el 'ser aquí' como un resultado ${ }^{47}$. Afirma en esta dirección A.L. González:

"Incluso la existentia, resultado o factum de la constitución del ente, es un término de poca relevancia teorética. El hecho de existir no es un principio metafísico, pues pertenece a un ente metafísicamente ya constituido, es decir compuesto de ser y esencia; en todo caso, es en el ente un efecto consiguiente a la posesión de esse"48.

Por tanto, la existentia señala el ente actualizado, la cosa que posee una existencia actual, mientras que el esse es aquel principio por el que un ente es. Los entes no se distinguen por la existencia, ésta es algo que a todos acontece del mismo modo ${ }^{49}$. En fin, y con palabras de Gilson: "Una vez compuestos el esse y la esencia tomistas, no hay ningún ser de existencia actual que explicar"50.

En cuanto a la influencia de Aristóteles sobre Cayetano se pueden hacer algunas acotaciones. En principio ya hemos notado que las nociones esse essentiae y esse actualis existentiae no tienen un basamento en la letra del Estagirita, si bien puede haber una coincidencia entre la existencia aristotélica y

[45] Gilson Étienne, Cajétan et l'existence, p. 272.

[46] Fabro, Cornelio. Tomismo e Pensiero Moderno, p. 103.

[47] Cfr. Clavell, Luis, Il nome metafísico di Dio, Divus Thomas 78, 1975, pp. 81-82.

[48] González, Ángel L. Ser y Participación, p. 116.

[49] Cfr. Llano, Alejandro. Metafísica y Lenguaje, Pamplona, Ed. EUNSA, 2011, p. 253.

[50] Gilson Étienne, Cajétan et l’existence, p. 272.

THÉMATA. Revista de Filosofía, Nº 49 enero-junio (2014) pp.: 235-254

doi: 10.12795/themata.2014.i49.13 
el esse actualis existentiae del que habla Tomás de Vio. Mas esta concurrencia terminológica no deja de ser fortuita, puesto que según los textos analizados Cayetano no se ha apoyado en el maestro del Liceo.

Por otro lado, se ha querido ver en Aristóteles un obstáculo para Cayetano al momento de hacer su exégesis en torno al actus essendi tomasiano. Empero, la metafísica del Filósofo no parece haber buscado un principio que explicara la totalidad de lo real, esto es, no parece haber indagado sobre un principio que trascendiera el mero hecho de la misma existencia de las cosas reales, lo que, por otra parte, es lógico en tanto que para él el cosmos era inengendrado. Aristóteles centra su investigación metafísica en la sustancia, y la sustancia por antonomasia o en sí es la forma ${ }^{51}$. Allí radica para el Filósofo el último fundamento o causa de lo real ${ }^{52}$.

También es cierto que para los teólogos y filósofos de la época de Cayetano si algún concepto no se encontraba en Aristóteles entonces no pertenecía a la filosofía ${ }^{53}$. Y es sabido que la noción de un actus essendi dado y sostenido por Dios en las criaturas no se hallaba en el maestro del Liceo. Así, por tanto, creemos que para el Cardenal, no se trataría de una noción filosófica per se loquendo.

En este contexto pueden entenderse las fuertes aseveraciones de Gilson: "una cosa está clara al menos en mi cabeza: el peor enemigo de Santo Tomás, incluso en la orden dominica, ha sido Aristóteles, cuyo profeta es Cayetano" ${ }^{54}$. Estas palabras no deben prestarse a malentendidos. No es que el medievalista francés culpe al pensador griego de las falencias interpretativas de Cayetano, sino que en todo caso el responsable de no haber ido más allá de Aristóteles es el mismo Cardenal. Como lo explica el profesor Saranyana:

\footnotetext{
"recuérdese que lo propio del tomismo es completar la posición aristotélica con el descubrimiento de la trascendentalidad del esse. Así pues, Cayetano sería, pura y llanamente, un aristotélico convencido, como le correspondía por haberse formado en Padua, aunque camuflado bajo ropaje tomista [...]"55.
}

Como bien afirma el autor, Cayetano estudió y enseñó en Padua, uno de los focos del averroísmo latino por esa época. Este tipo de aristotelismo pre-

[51] Si bien per se la sustancia por excelencia es la forma, quad nos es el compuesto. Para ver esta afirmación en detalle cfr. Aristóteles, Metafísica, VII, caps. 4-6 y 10-12.

[52] Cfr. Reale, Giovanni. Guía de lectura de la metafísica de Aristóteles, trad. J. M López de Castro, Barcelona, Ed. Herder, 2003, p. 168.

[53] Gilson, Étienne, Autour de Pomponazzi, Archives d'histoire doctrinale et littéraire du Moyen Age 28, 1961, p. 173.

[54] Carta de E. Gilson a J. Maritain del 6 de abril de 1953 en Prouvost, Géry (ed.). Étienne Gilson et Jacques Maritain. Deux approaches de l'etre. Correspondance 1923-1971. Paris, Ed. Vrin, 1991, p. 188.

[55] Saranyana, Josep-Ignasi. Historia de la Filosofía Medieval, Pamplona, Ed. EUNSA, 2003, p. 429.

THÉMATA. Revista de Filosofía, Nº49 enero-junio (2014) pp.: 235-254

doi: 10.12795/themata.2014.i49.13 
tendió hacer una lectura de Aristóteles lo más pura posible, sin contaminación alguna de la teología cristiana. Por ello el Aristóteles averroísta llevaba a sostener tesis contrarias a la fe, conduciendo a la postre a un filosofismo escindido de la teología ${ }^{56}$, o a un ejercicio de la razón filosófica separado del intellectus fidei. En este contexto, no es de extrañar, además, que Cayetano haya llegado a algunas conclusiones tan distantes del Aquinate, como la que sostenía que no es posible demostrar por la razón la inmortalidad del alma ${ }^{57}$ o aquella que afirmaba que las cinco vías tomasianas concluyen en la existencia de un ser superior pero al que el Cardenal se resistía a llamarle Dios ${ }^{58}$.

En suma, y si lo que hemos afirmado a lo largo de este trabajo es acertado, podemos especular que Cayetano tuvo dos tipos de influencias que lo condicionaron a incorporar un lenguaje ajeno a la doctrina de Santo Tomás, como son los términos esse essentiae y esse actualis existentiae. Nos referimos al escotismo y al averroísmo latino. En el caso del primero, las permanentes discusiones de nuestro autor con esta corriente de pensamiento podrían haber conducido al comentador de Gaeta a usar sus mismos términos y finalmente a la contaminación del tomismo por parte del escotismo. Con respecto al segundo, el influjo de esta doctrina podría haber llevado al Cardenal a una separación entre teología y filosofía o entre fe y razón, lo cual lo empujó finalmente a formular una metafísica diferente de la de Santo Tomás en la que las nociones de ens y esse ya no tendrán el sentido que tenían en el Aquinate. Al parecer, la síntesis de estas dos influencias habría llevado al gran comentador dominico a no reconocer la original e inestimable síntesis filosófico-teológica a la que arribó el Doctor Común con la doctrina del actus essendi y con otros temas anejos a esta enseñanza.

[56] Cfr. Filippi, Silvana, La restitución de valor inteligible al conocimiento sensible en el realismo medieval, Scripta Mediaevalia, 3, 2010, pp. 41-42.

[57] Cfr. Manzanedo, Marcos, La inmortalidad del alma humana según Cayetano, Angelicum 76, 1999, pp. 309-340.

[58] Cfr. Gelonch, Santiago y Muñoz, Ceferino, Algunas inflexiones en la cuestión Si Dios es: santo Tomás, Cayetano y Platón. En Juan José Herrera (ed.), Fuentes del Pensamiento Medieval, San Miguel de Tucumán, Ed. UNSTA, 2012, pp. 330-333.

THÉMATA. Revista de Filosofía, Nº 49 enero-junio (2014) pp.: 235-254

doi: 10.12795/themata.2014.i49.13 


\section{Referencias bibliográficas:}

Aristóteles. Analíticos Posteriores, Madrid, Ed. Gredos, 2007, trad. Miguel Candel Sanmartin.

Bañez, Domingo. Scholastica commenttaria in Primam Partem Summae Theologicae D. Thomae Aquinalis, Madrid-Valencia, ed. Luis Urbano, t. I, 1934.

Busa, Roberto, (auctore). Thomae Aquinatis Opera Omnia: cum hypertextibus in CD-ROM. Milano: Editoria Elettronica Editel, 1992.

Cayetano, Comentaria in De ente et essentia D. Thomae Aquinatis, Roma, Edición H. Laurent, Marietti, 1934.

- De nominum analogia. Texto latino según edición Zammit O.P. (con notas de Zammit), trad. y notas de Guido Soaje Ramos, Mendoza, Universidad Nacional de Cuyo, Instituto de Filosofía, 1949.

- Summa Theologica cum comentario Cardenali Caietani, de la Opera Omnia, Romae, ed. Leonina, 1883.

- Commentaria in Posteriora Analytica Aristotelis. Textus ex editione Lugdunensi (1579) exerptus et a E. Babin et W. Baumgaertner. Exaratus et emendatus. Liber I (1950), Les editions de l'Univertité Laval, Faculté de Philosophie, Québec, et Liber II (1951).

Clavell, Luis, Il nome metafísico di Dio, Divus Thomas 78, 1975, pp. 69-85.

Courtine, Jean-Francois. Suarez et le systeme de la métaphysique, Paris, Ed. PUF, 1990.

Echauri, Raúl, Esencia y existencia en Aristóteles, Anuario Filosófico, 8, 1975, pp. 119-129.

Elders, Leo, Cayetano, comentador de la Suma de teología de Santo Tomás, (2011). Disponible en: http://bibliotecadigital.uca.edu.ar/repositorio/ponencias/ cayetano-comentador-suma-teologia-tomas.pdf.

Fabro, Cornelio. Dall'essere al esistente, Brescia, Ed. Morcelliana 1957.

- Tomismo e Pensiero Moderno, Roma, Pontificia Università Lateranense, 1969. 
Filippi, Silvana, La restitución de valor inteligible al conocimiento sensible en el realismo medieval, Scripta Mediaevalia, 3, 2010, pp. 29-46.

García Cuadrado, José A. La luz del intelecto agente. Estudio desde la metafísica de Bañez, Pamplona, ed. EUNSA, 1998.

Gilson, Étienne, Cajétan et l’existence, Tijdschrift voor Philosophie 15, 1953, pp. 267-286.

- $\quad$ Cajetán et l'humanisme théologique, Archives d'histoire doctrinale et littéraire du Moyen Age 30, 1955, pp. 113-136.

- $\quad$ History of Christian Philosophy in the Middle Ages, New York, Ed. Random House, 1955.

- $\quad$ Autour de Pomponazzi, Archives d'histoire doctrinale et littéraire du Moyen Age 28, 1961, pp. 163-279.

- $\quad$ El ser y los filósofos, Pamplona, Ed. EUNSA, 2005.

González, Ángel L. Ser y Participación. Estudio sobre la cuarta vía de Tomás de Aquino, Pamplona, Ed. EUNSA, 2001.

Heidegger, Martin. Carta sobre el humanismo, trad. Helena Cortés y Arturo Leyte, Madrid, Ed. Alianza, 2000.

Llano, Alejandro. Metafísica y Lenguaje, Pamplona, Ed. EUNSA, 2011.

Manzanedo, Marcos, La inmortalidad del alma humana según Cayetano, Angelicum 76, 1999, pp. 309-340.

Mcinerny, Ralph. Praeambula Fidei: Thomism and the God of the Philosophers, Washington, The Catholic University of America Press, 2006.

Muñoz, Ceferino y Gelonch, Santiago, Algunas inflexiones en la cuestión Si Dios es: santo Tomás, Cayetano y Platón. En Juan José Herrera (ed.), Fuentes del Pensamiento Medieval, San Miguel de Tucumán, Ed. UNSTA, 2012, pp. 327-339.

Prouvost, Géry (ed.). Étienne Gilson et Jacques Maritain. Deux approaches de l'etre. Correspondance 1923-1971. Paris, Ed. Vrin, 1991. 
- $\quad$ Thomas d’Aquin et le thomistes, París, Les Éditions du Cerf, 1996.

Reale, Giovanni. Guía de lectura de la metafísica de Aristóteles, trad. J. M López de Castro, Barcelona, Ed. Herder, 2003.

Reilly, John P., Cajetan: essentialist or existentialist?, The New Scholasticism 41, 1967.

Saranyana, Josep-Ignasi. Historia de la Filosofía Medieval, Pamplona, Ed. EUNSA, 2003.

Silvestre de Ferrara, in Sancti Thomae Aquinatis, Summa Contra Gentiles (cum comentario Silvestre de Ferrara), vol. XIII de la Opera Omnia, Romae, ed. Leonina, 1883, Lib. II, Cap. LIV.

Tomás de Aquino. El ente y la esencia, trad., estudio preliminar y notas de Eudaldo Forment, Pamplona, ed. EUNSA, 2006.

Van Steenberghen, Fernand, Le problème de l'existence de Dieu dans le De ente et essentia de Saint Thomas d'Aquin, Mélanges de Fhellinck, vol. II, Lovaina, 1951. 